The numbers of cases reported yearly to the Public Health Laboratory Service Communicable Disease Surveillance Centre is about 3000 . Among children aged under 5 cryptosporidiosis may be found more commonly than salmonella infection. Detailed follow up study of cases diagnosed by the laboratory commonly shows other cases among contacts, including adults, and the number of cases reported clearly represents only a proportion of the actual incidence.

DAVID CASEMORE

Public Health Laboratory,

Glan Clwyd Hospital,

Bodelwyddan,

Rhyl

Clwyd LL18 5UJ

1 Galbraith NS. Cryptosporidiosis: another source. $\mathrm{Br}$ Med $\mathcal{f}$ 1989:298:276-7. (4 February.)

2 Casemore DP. Sheep as a source of human cryptosporidiosis. $f$ Infect (in press).

3 Casemore DP. The epidemiology of human cryptosporidiosis. In: Angus KW, Blewett DA, eds. Cryptosporidium and cryptosporidiosis. Proceedings of an international workshop. Edinburgh: sporidiosis. Proceedings of an inte

Palmer SR, Biffin A. Cryptosporidiosis. PHLS Digest 1987;4: $6-7$

Casemore DP. Cryptosporidiosis. PHLS Digest 1987;4:1-5.

\section{Chlormethiazole and treatment of delirium tremens}

SIR, - I would like to comment on the editorial by Dr Jonathan Chick on delirium tremens, with particular reference to the statement that intravenous chlormethiazole causes death from respiratory depression. I have used intravenous chlormethiazole extensively, both in anaesthesia and in intensive care, and I have never seen respiratory depression even when the patients were anaesthetised with the drug - that is, much more deeply sedated than is necessary in the treatment of delirium tremens. When the drug is given intravenously in general wards the patient's airways may become obstructed. The problem of oversedation is compounded when chlormethiazole is given intravenously as a last resort to treat delirium tremens in patients who have already received large doses of other sedatives, particularly benzodiazepines. Chlormethiazole by the intravenous route is seldom required in alcohol withdrawal and should be used only in intensive care units whose staff are well trained in airways control.

As I understand it, the prime aims in treating alcohol withdrawal are sedation, prevention of convulsions, and suppression of autonomic hyperexcitability. If delirium tremens supervenes further sedation becomes urgent if death is to be avoided. There is particular merit in using a single drug rather than resorting to polypharmacy, which Dr Chick, perhaps inadvertently, seems to be recommending. Good results have been obtained with chlormethiazole. The paper of Schied et al, quoted in the editorial as evidence of the danger of intravenous chlormethiazole, ${ }^{2}$ showed that in an extensive survey of West German psychiatric clinics no deaths occurred over 10 years in institutions having access to intensive care facilities.

Schied's group used a combination of oral and intravenous chlormethiazole and reported only one death attributable to "respiratory depression"; this occurred three days after the patient, who could not be intubated, had had extensive surgery for a carcinoma on the floor of the mouth. ${ }^{3}$ Since chlormethiazole had been used routinely they found that the mortality associated with delirium tremens had fallen from $15 \%$ to $1 \cdot 7 \%$.

I am also concerned by Dr Chick's advice to give drugs such as chlordiazepoxide and diazepam hourly, both drugs having extremely long half lives of around 24 hours or more. These drugs are surely the most likely to cause the cumulative sedation Dr Chick is anxious to avoid, particularly if liver disease is present. ${ }^{+5}$ Diazepam, incidentally, is a respiratory depressant ${ }^{6}$ with a potency equal to that of morphine.

Neuroleptics such as haloperidol and droperidol may be widely used in treating delerium tremens, but the information on their data sheets specifically warns against their use in liver disease and in combination with alcohol. They also lower the threshold for convulsions. It is also difficult to believe that intravenous ethanol will shorten the recovery from delirium tremens.

Dr Chick's editorial does a service by emphasising close observation of patients with alcohol withdrawal and the early detection of delirium tremens. Treatment is now effective and the mortality should approach zero, but drugs must be used with a proper regard for their pharmacokinetic and pharmacodynamic behaviour.

D B SCOTT

Edinburgh EH1 3EP

1 Chick J. Delirium tremens. Br Med f 1989;298:3-4. (7 January.)

2 Schied HW, Braunschweiger M, Schupmann A. Treatment of delerium tremens in German psychiatric hospitals: results of a recent survey. Acta Psychiatr Scand 1986;73:153-6.

3 Schied HW, Kimmerle K, Braunschweiger M. A retrospective comparison of delirium tremens cases before and after the availability of chlormethiazole. Acta Psychiar Scand 1986; 73:157-61.

4 Burroughs AK, Morgan MY, Sherlock S. Double-blind controlled trial of bromocriptine, chlordiazopoxide and chlormethiazule for alcohol withdrawal symptoms. Alcohol 1985; methiazole for

5 Andreasen PB, Hendel J, Greisen G, Hvidberg ES. Pharmacokinetics of diazepam in disordered liver function. Eur $\mathcal{J}$ Clin Pharmacol 1976;10:115-20

6 Gilmartin JJ, Corris PA, Stone TN, Veale D, Gibson GJ. Effects of diazepam and chlormethiazole on ventilatory control in normal subjects. Br f Clin Pharmacol 1988:25:766-70.

7 Jordan C, Lehane JR, Jones JG. Respiratory depression with diazepam - reversal with high dose naloxone. Anesthesiology $1980 ; 53: 293-8$.

\section{Women and HIV}

SIR,-HIV infection continues to present new challenges in clinical management, especially in the issues surrounding a potentially lethal vertically transmitted agent in fertile women.

Contraception in HIV infected women is a thorny topic, and I think we should be honest in that we have only opinion, and no hard evidence, on which to base our advice. Most women with HIV infection in Europe and the United States are not at high risk of aquiring sexually transmitted diseases, and the cited risk of pelvic infection associated with intrauterine devices is not confirmed. There is evidence that people infected with HIV through drug use can take non-opiate drugs reliably (A Spears et al, fourth international conference on AIDS, Stockholm, 1988), ${ }^{2}$ and noncompliance with oral treatment in current or former drug users should not be automatically assumed. We need carefully designed long term studies to assess risks and benefits in terms of disease progression, infectivity, and transmission with differing contraceptive modes such as sterilisation, barrier contraception, and combined hormonal or progesterone only agents. Until such evidence is available any of the above methods may be considered to be the right choice for individual women with HIV infection

Women have the main role in reproduction, and the psychological wellbeing associated with potential fertility in HIV infected women has been understated. There is already evidence that the presence or absence of HIV infection in comparable groups of women does not affect reproductive behaviour (P A Selwyn et al, fourth international conference on AIDS, Stockholm, 1988) and it would be short sighted of the profession to assume that termination or sterilisation is a solution to these dilemmas. What we urgently need is the establishment of studies looking at the association of maternal variables with HIV transmission to children. The now clearly identified laboratory markers of progression in HIV infection could well also be markers for vertical transmission. Such knowledge would be of inestimable help in our management of fertile women with HIV infection. It will also be a necessary prelude to any consideration of theraputic attempts to block HIV transmission to fetuses at high risk.

C J N LACEY

Department of Genitourinary Medicine,

General Infirmary

Leeds LS1 3EX

Bradbeer C. Women and HIV. Br Med f 1989;298:342-3. (11 February.

2 Johnstone FD, MacCallum L, Brettle R, Inglis JM, Peuchere JF. Does infection with HIV affect the outcome of pregnancy? BrMed F 1988;296:467.

\section{Tuberculosis and HIV infection in Africa}

SIR, - The recent report of high rates of HIV infection in Zambian patients with suspected or definite pulmonary tuberculosis ${ }^{1}$ confirmed previous studies ${ }^{23}$ in Africa showing an association between HIV infection and tuberculosis.

In Africa nearly all antituberculosis chemotherapy regimens entail the use of streptomycin by daily intramuscular injection for one or two months as part of the initial intensive phase of treatment. Epidemiological evidence from central Africa suggests that rates of HIV infection in adults and children are associated with an increased number of medical injections. ${ }^{+}$In many clinics and rural health centres disposable needles and syringes are often not available or are reused, and sterilisation practices may sometimes be poor. Although we are unaware of any studies that show iatrogenic spread of HIV infection in patients receiving treatment for tuberculosis, the use of daily injections in patients with a high prevalence of HIV infection is a cause for concern.

If streptomycin was considered to be essential in treatment regimens (because of its low cost and effect on patient compliance) it would be vital to ensure an adequate supply of syringes and needles in all tuberculosis control programmes in Africa. An alternative, albeit costly, solution would be to abandon the use of streptomycin in favour of oral regimens alone.

With the growing epidemic of AIDS in Africa we believe that it is important to raise these issues so that at least within the health sector the spread of HIV infection from one patient to another is minimised.

D J ROBERTS A D HARRIES

Department of Tropical Medicine and Infectious Diseases,

Liverpool School of Tropical Medicine, Liverpool L3 5QA

1 Meeran K. Prevalence of HIV infection among patients with leprosy and tuberculosis in rural Zambia. Br Med f 1989;298: 364-5. (11 February.)

2 Van de Perre P, Rouvroy D, Lepage P, et al. Acquired immunodeficiency syndrome in Rwanda. Lancet 1984;ii:62-5.

3 Mann JM, Snider DE, Francis H, et al. Association between HTLV-III/LAV infection and tuberculosis in developing countries. FAMA 1986;256:346.

4 Piot P, Caraël M. Epidemiological and sociological aspects of HIV infection in developing countries Br Med Bull 1988;44 68-88.

\section{Heart disease mortality}

SIR, - The news item on the National Audit Office report National Health Service: Coronary Heart Disease reproduces two graphs of coronary heart disease mortality data taken from the report and attributed to the World Health Organisation, one of which is correct and the other of which is unorthodox and potentially misleading. 